\title{
PROFIL DAN RELEVANSI LULUSAN JURUSAN PENDIDIKAN TEKNIK MESIN DENGAN KEBUTUHAN KERJA
}

\author{
Arianto Leman S.*, Wagiran, Edy Purnomo, Mujiyono
}

Jurusan Pendidikan teknik Mesin, Universitas Negeri Yogyakarta

\begin{abstract}
This research aims at revealing the graduate profiles and their relevance to the competence needed for S1(bachelor) of the Department of Engineering Education, The faculty of Engineering, State University of Yogyakarta. This is a survey research with descriptive method. The population is all the Strata 1 (S1) graduates of the Department of Engineering Education, The faculty of Engineering, State University of Yogyakarta graduated in 2011-2014. The data were taken by questionnaire, phone interview, and snowball sampling. The data were analyzed descriptively. The result shows that the $\mathrm{S} 1$ graduates have got jobs within four months of waiting time. The job sectors cover education, entrepreneurship, mechanical engineering, and non-mechanical engineering employment. Most of the graduates work on mechanical engineering in some industries. The appropriateness of their relevance to the competences needed in working field reaches $88 \%$, that is, most of the graduates work in industrial sectors.
\end{abstract}

Keywords: graduates profiles, competence, engineering education

\begin{abstract}
Abstrak: Penelitian ini bertujuan untuk mengungkap profil dan relevansi lulusan dengan kompetensi yang dibutuhkan lulusan S1 Kependidikan Jurusan Pendidikan Teknik Mesin Fakultas Teknik Universitas Negeri Yogyakarta (JPTM FTUNY). Penelitian ini merupakan penelitian survey dengan metode deskriptif. Populasi penelitian adalah seluruh lulusan S1 JPTM FT UNY tahun lulus 2011-2014. Data diambil dengan angket, wawancara melalui telepon dan snowball sampling. Data dianalisis secara deskriptif. Hasil penelitian menunjukkan bahwa lulusan S1 JPTM telah mendapat pekerjaan dengan rata-rata masa tunggu 4 bulan. Bidang pekerjaan terdiri dari pendidik, wirausaha, karyawan yang tidak terkait dengan bidang teknik mesin, dan karyawan yang terkait dengan bidang teknik mesin. Sebagian besar lulusan bekerja di industri bidang teknik mesin. Kesesuaian relevansi lulusan dengan kompetensi yang dibutuhkan oleh dunia kerja mencapai angka 88\%). Lulusan lebih banyak bekerja disektor industri.
\end{abstract}

Kata kunci: Profil lulusan, kompetensi, pendidikan teknik mesin.

Alamat korespondensi: Jl.Colombo No.1, Caturtunggal.Depok .Yogyakarta

e-mail: arianto_ls@uny.ac.id; 


\section{PENDAHULUAN}

Jurusan Pendidikan Teknik Mesin (JPTM) merupakan bagian dari Fakultas Teknik Universitas Negeri Yogyakarta (FT UNY) sebagai Lembaga Pendidikan Tenaga Kependidikan (LPTK) yang memiliki tugas pokok dan fungsi menghasilkan calon guru kejuruan dan ahli madya teknik yang profesional. Sebagai wujud pertanggungjawaban pelaksanaan tugas pokok dan fungsi tersebut, lembaga pendidikan tinggi dituntut mampu menghasilkan lulusan yang memiliki kompetensi utuh sesuai dengan kebutuhan lapangan kerja. Lembaga pendidikan tinggi dituntut mampu merencanakan, melaksanakan, dan mengevaluasi kurikulum yang memiliki relevansi tinggi. Hal ini tampak dari standar kompetensi lulusan dan penjabarannya dalam silabus dan rencana perkuliahan. Informasi dari dunia kerja sangat diperlukan dalam upaya menghasilkan lulusan yang memiliki kompetensi selaras dengan kebutuhan dunia kerja.

Studi penelusuran adalah studi untuk melacak anak-anak, keluarga mereka, pekerja, masyarakat atau organisasi, beberapa tahun setelah mereka berpartisipasi dalam suatu program. Studi penelusuran merupakan suatu upaya penelitian untuk mengetahui apakah ada sesuatu yang tersisa dari sebuah program yang beberapa tahun sebelumnya dilakukan untuk mempengaruhi kehidupan manusia (Cohen, 2004: 17). Studi penelusuran merupakan upaya paling efektif dalam menjaring masukan dari dunia kerja untuk mengetahui relevansi kompetensi lulusan dengan pasar kerja. Studi penelusuran efektif dalam mengukur dan melacak kinerja lulusan sehingga dapat diperoleh indikator yang jelas tentang jumlah, profil kerja masa mendatang serta pelatihan yang diperlukan. Melalui studi penelusuran lembaga pendidikan tinggi dapat mempersiapkan isi dan sistem pendidikannya agar lulusan yang dihasilkan dapat beradaptasi dengan dunia kerja. Menurut Ugwuonah \& Omeje (1998), tujuan utama dari studi penelusuran adalah: (1) Untuk menentukan faktor-faktor yang mempengaruhi responden (lulusan) memilih institusi yang lebih tinggi (universitas atau politeknik); (2) Untuk memastikan kondisi pendidikan pada lembaga responden atau lulusan; (3) Untuk mengetahui bagaimana responden memperoleh pekerjaan pertama mereka serta pertimbangan yang memotivasi mereka untuk mengambil pekerjaan tersebut; (4) Untuk menentukan kesesuaian pekerjaan 
spesifik responden (lulusan) terkait dengan bidang studi mereka; (5) Untuk menyelidiki kegunaan atau sebaliknya dari kedua aspek teoritis dan praktis dari pendidikan responden untuk pekerjaan mereka; (6) Untuk memastikan struktur lapangan kerja, upah dan kesejahteraan responden dalam hal pekerjaan sampingan, penghasilan dan tunjangan di tempat kerja; (7) Untuk mengakses persepsi responden dan sikap terhadap karakteristik pekerjaan mereka, harapan karir, aktualisasi dan perubahan. Tujuan studi penelusuran dalam penelitian ini adalah mengidentifikasikan kualitas lulusan. Informasi yang dapat diperoleh dari studi penelusuran antara lain: (1) Profil kompetensi alumni, (2) Relevansi kurikulum yang diterapkan dengan kebutuhan pasar kerja, (3) Memberi masukan pada pengembangan kurikulum, (4) Memperoleh gambaran kompetensi yang dibutuhkan pengguna alumni, dan (5) Memberi masukan untuk mendapatkan pendanaan kompetitif dari berbagai sumber.

Selain tujuan di atas, studi penelusuran juga sangat penting artinya guna mengetahui kinerja alumni sekaligus sebagai gambaran kinerja jurusan/program studi sebagai bagian dari penilaian akreditasi. Makin baik kinerja alumni menunjukkan makin baiknya kinerja jurusan/program studi dalam menyiapkan lulusannya. Makin baiknya kinerja jurusan/prodi dalam menyiapkan lulusan akan memberikan kontribusi capaian skor akreditasi sebagai bagian dari penjaminan mutu lembaga.Proses untuk melaksanakan studi pelacakan terdiri dari enam kegiatan utama (USAID, 1998:6-9). Kegiatan ini harus dilakukan untuk mencapai implementasi yang efisien dan efektif dari studi dan hasil yang bermanfaat. Kegiatan tersebut adalah: (1) Kebutuhan informasi dan pengumpulan data yang teridentifikasi; (2) Menyediakan informasi yang diperoleh dari populasi dan memilih bagian yang representatif, yang merupakan sampel; (3) Mengumpulkan informasi; (4) Pengumpulan Data.; (5) Analisis data.; (6) Temuan dari laporan ini merupakan langkah terakhir adalah presentasi hasil studi pelacakan.

Mengingat pentingnya studi penelusuran tersebut, sudah saatnya bila kegiatan ataupun program tersebut dilakukan secara rutin sebagai bagian dari proses penjaminan mutu. Berdasarkan pemikiran tersebut maka studi penelusuran alumni Jurusan Pendidikan Teknik Mesin merupakan kegiatan dan 
program yang harus dilakukan secara periodik. Berdasarkan pemikiran tersebut, penelitian ini dilakukan untuk menungkap profil alumni dan relevansi kurikulum dengan tuntutan dunia kerja.

\section{METODE PENELITIAN}

Penelitian ini merupakan penelitian survei yang dilakukan untuk mendapatkan data profil lulusan program studi S1JPTM FT UNYtahun 2011-2014. Penelitan ini dilakukan terutama dalam lingkup Provinsi DIY, Jawa Tengah. Namun demikian kawasan tersebut dapat diperluas tergantung dari keberadaan alumni yang dilacak. Penelitian dilaksanakan selama enam bulan efektif mulai bulan Mei - Agustus 2015.

Populasi pada penelitian ini adalah seluruh alumni Jurusan Pendidikan Teknik Mesin Tahun 2011-2014. Setiap tahun JPTM menerima 2 kelas program studi S1 kependidikan dengan jumlah mahasiswa per kelas rata-rata 40 orang. Jumlah sampel yang berhasil ditulusuri sebanyak 116 orang. Teknik pengambilan data dilakukan dengan memanfaatkan telepon, grup-grup dalam media sosial seperti WA, facebook, twitter dan se- bagainya. Teknik snowball juga diterapkan untuk sebanyak-banyaknya memperoleh data.

Pengumpulan data dalam penelitian ini menggunakan metode angket, wawancara, dan dokumentasi. Penyusunan instrumen diawali dengan penyusunan kisi-kisi, validasi, penyempurnaan dan finalisasi instrumen. Data profil lulusan Jurusan Pendidkan Teknik Mesin dalam penelitian ini dianalisis dengan analisis deskriptif kuantitatif, sedangkan untuk menganalisis relevansi kompetensi lulusan dengan kebutuhan dunia kerja digunakan analisis deskriptif kuantitatif dan kualitatif.

\section{PEMBAHASAN}

\section{Profil Pekerjaan}

Responden penelitian terbagi dalam dua kelompok,yaitu: Kelompok I, lulusan tahun 2011-2012 dan kelompok II, lulusan tahun 2013-2014. Jumlah responden kelompok I dan II berturutturut adalah 55 orang dan 61 orang. Sebagian besar reponden kelompok I telah bekerja dengan rata-rata masa tunggu mendapat pekerjaan 4 bulan. Satu orang melanjutkan ke jenjang pendidikan S2 di UNY dan 3 orang belum bekerja. Responden pada kelompok II sebagian besar juga telah 
bekerja dengan rata-rata masa tunggu mendapatkan pekerjaan 4 bulan. Bahkan terdapat 6 (enam) orang lulusan yang telah diterima bekerja sebelum yudisium dilaksanakan. Tiga orang lulusan dari kelompok II melanjutkan ke jenjang pendidikan S2 di UNY dan 6 orang belum bekerja.

Jenis pekerjaan yang digeluti oleh lulusan JPTM FT UNY tahun 2011-2014 secara umum dapat dibagi menjadi empat bidang, yaitu: (1) Pendidikan dan pengajaran meliputi SD, SMK, SMA, Perguruan Tinggi maupun lembaga pendidikan lainnya; (2) Wirausaha; (3) Karyawan yang tidak terkait dengan bidang Teknik Mesin; dan (4) Perusahaan atau Industri yang terkait dengan bidang Teknik Mesin. Uraian profil pekerjaan lulusan S1 JPTM FT UNY tahun 2011-2014 diatas dapat dirangkum dan disajikan pada tabel 1 dan 2 .

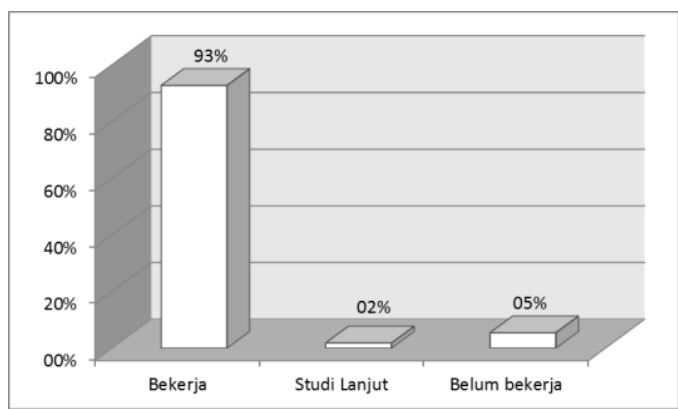

Gambar 1. Profil Lulusan JPTM FT UNY tahun 2011-2012

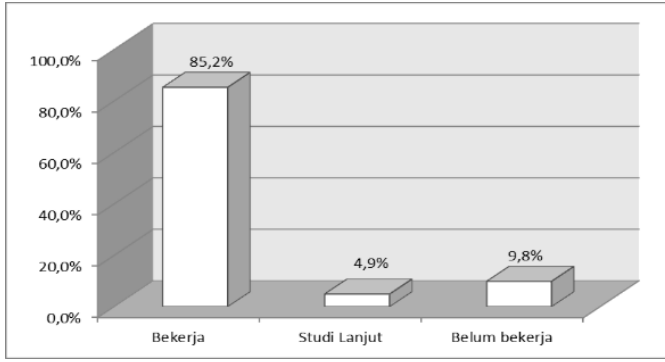

Gambar 2. Profil Lulusan JPTM FT UNY tahun 2013-2014

Tabel 1. Profil lulusan JPTM FT UNY 2011-2012

\begin{tabular}{clcc}
\hline No & Pekerjaan & Jumlah & Persentase \\
\hline $\mathbf{1}$ & Guru SMK & 14 & 25,45 \\
$\mathbf{2}$ & Instruktur & 3 & 5,45 \\
$\mathbf{3}$ & Wirausaha & 2 & 3,64 \\
$\mathbf{4}$ & Instansi yang & 3 & 5,45 \\
& tidak terkait & & \\
& bidang Teknik & & \\
& Mesin & & \\
$\mathbf{5}$ & Industri yang & 29 & 52,73 \\
& terkait bidang & & \\
& Teknik Mesin & & \\
$\mathbf{6}$ & Lanjut S2 & 1 & 1,82 \\
$\mathbf{7}$ & Belum bekerja & 3 & 5,45 \\
& Jumlah & 55 & 100,00 \\
\hline
\end{tabular}

Tabel 2. Profil lulusan JPTM FT UNY 2013-2014

\begin{tabular}{llcc}
\hline No & \multicolumn{1}{c}{ Pekerjaan } & Jumlah & $\begin{array}{c}\text { Persen } \\
\text { tase }\end{array}$ \\
\hline $\mathbf{1}$ & Guru SMK & 10 & 16,39 \\
$\mathbf{2}$ & Guru SMA & 1 & 1,64 \\
$\mathbf{3}$ & Dosen PTS & 1 & 1,64 \\
$\mathbf{4}$ & Wirausaha & 2 & 3,28 \\
$\mathbf{5}$ & Instansi yang tidak & 6 & 9,84 \\
& terkait bidang Teknik & & \\
& Mesin & & \\
$\mathbf{6}$ & Industri yang terkait & 32 & 52,46 \\
& bidang Teknik Mesin & & \\
$\mathbf{7}$ & Lanjut S2 di UNY & 3 & 4,92 \\
$\mathbf{8}$ & Belum bekerja & 6 & 9,84 \\
& Jumlah & 61 & 100,0 \\
\hline
\end{tabular}

Profil lulusan JPTM FT UNY tahun 2011-2012 tampak pada Gambar 1, sedang profil lulusan JPTM FT UNY tahun 2013-2014 tampak pada Gambar 2. 
Dari kedua gambar tersebut tampak bahwa sebagian besar responden yang berhasil di data telah bekerja baik dibidang pendidikan, industri yang terkait dengan bidang teknik mesin maupun pada instansi yang tidak terkait dengan bidang teknik mesin serta sebagian merintis wira usaha. Sebagian kecil melanjutkan studi S2 di UNY dan sebagian kecil lainnya belum bekerja. Profil ini tampak pada lulusan tahun 20112012 maupun tahun 2013-2014. Secara umum profil kedua kelompok tersebut adalah sama. Hal sejalan dengan penelusuran yang dilakukan oleh Sukardi (2011: 196 - 201) terhadap lulusan S1 kependidikan FT UNY. Tampak bahwa perbandingan kompetesnsi dan kesempatan bekerja lulusan S1 JPTM FT UNY sudah baik.

Data hasil penelusuran pada Tabel 1 dan 2 menunjukkan fakta tersebut, yaitu hanya $25 \%$ responden bekerja dibidang pendidikan. Kondisi ini berbeda dengan hasil penelusuran yang dilakukan oleh Saliman (2015: 83-100) yang menemukan $60 \%$ responden bekerja di bidang pendidikan maupun Setiya Fakhrulisah \& Muis (2005) yang menemukan $99 \%$ responden bekerja dibidang pendidikan. Implikasi hsail penelusuran ini adalah bidang pekerjaan yang mungkin digeluti oleh lulusan JPTM FT UNY cukup luas. Sejalan dengan Dardiri. (2011: 91-104), JPTM FT UNY perlu mengembangkan diversifikasi kompetensi untuk mengakomodasi bidang pekerjaan yang lebih luas bagi lulusannya agar lebih kompetitif dalam memperoleh peluang pekerjaan.

\section{Profil Tempat Bekerja}

Berdasar uraian sebelumnya tampak sebagian besar lulusan S1 JPTM FT UNY bekerja di industri yang terkait bidang Teknik Mesin. Tabel 3 memperlihatkan industri-industri terkait bidang teknik mesin tempat bekerja kelompok I. Tabel 4 menyajikan instansi tempat bekerja kelompok I yang tidak terkait bidang teknik mesin, sedang Tabel 5 menunjukkan tempat bekerja kelompok I terkait bidang pendidikan. Lebih lanjut, Tabel 6 memperlihatkan industri-industri yang terkait bidang teknik mesin tempat bekerja kelompok II. Pada Tabel 7 disajikan instansi-instansi tempat bekerja kelompom II yang tidak terkait bidang teknik mesin, sedang Tabel 8 menunjukkan tempat bekerja kelompok II terkait bidang pendidikan. 
Tabel 3. Industri Yang Terkait Bidang Teknik Mesin Tempat Bekerja Lulusan S1 JPTM FT UNY Tahun 2011-2012

\begin{tabular}{|c|c|c|c|c|c|}
\hline No & Nama Industri & Alamat & No & Nama Industri & Alamat \\
\hline 1 & PT.Kobeindo Tractor & $\begin{array}{l}\text { Jl.Pasar Putih Raya } \\
\text { blok 5D, Ancol }\end{array}$ & 14 & PT. United Traktor & $\begin{array}{l}\text { Jl. Raya Bekasi Km. } 22 \\
\text { Cakung, Jakarta Timur }\end{array}$ \\
\hline 2 & Indomobil Nissan & Depok & 15 & PT. Kawan Lama & Semarang \\
\hline 3 & PT.Sapta Indra Sejati & $\begin{array}{l}\text { J1. TB. Simanjuntak } \\
\text { KM 18, Cimandale, } \\
\text { Jakarta Selatan }\end{array}$ & 16 & PT. Baker Huges & $\begin{array}{l}\text { Jl. Tenaga Uap, Kali } \\
\text { Japat, Ancol Timur, Ja- } \\
\text { karta Utara }\end{array}$ \\
\hline 4 & $\begin{array}{l}\text { PT Indomobil Srada } \\
\text { Nasional }\end{array}$ & VIP & 17 & $\begin{array}{l}\text { Kontraktor Tambang } \\
\text { Batu Bara }\end{array}$ & Kalimantan \\
\hline 5 & OLNEX PT AMK & Balikpapan & 18 & PT KAI & Bandung \\
\hline 6 & PAMA Persada & Kalimantan Timur & 19 & PT. Mitsuba & Purwakarta \\
\hline 7 & PT. Hepiterma & $\begin{array}{l}\text { Jl. Inti } 2 \text { Blok C No. } 5 \\
\text { Kawasan Hyundai, } \\
\text { Cikarang }\end{array}$ & 20 & PT. Pindo Deli & $\begin{array}{l}\text { Desa Kutamekar BTB } \\
\text { 6-9, Kec Teluk Jambe, } \\
\text { Karawang }\end{array}$ \\
\hline 8 & UT School & Jakarta Timur & 21 & ADR Group & Tangerang \\
\hline 9 & Izusu & $\begin{array}{l}\text { Jl. Sumber KM.30, } \\
\text { Blok 03, Jakarta Utara }\end{array}$ & 22 & PT. Rekplast Sidoarjo & $\begin{array}{l}\text { Jl. Brebeg Industri } 5 \\
\text { No. } 10 \text {, Sidoarjo }\end{array}$ \\
\hline 10 & Indomobil Nissan & $\begin{array}{l}\text { Jl. Soekarno Hatta } \\
\text { no. } 384 \text {, Bandung }\end{array}$ & 23 & PT Trakindo utama & $\begin{array}{l}\text { Balikpapan, } \\
\text { Kalimantan }\end{array}$ \\
\hline 11 & $\begin{array}{l}\text { Jasa Teknologi infor- } \\
\text { masi ITM }\end{array}$ & J1. Thamrin Jakarta & 24 & $\begin{array}{l}\text { PT. KPP (Kalimantan } \\
\text { Prima Persada) }\end{array}$ & Kalimantan Selatan \\
\hline $\begin{array}{l}12 \\
13\end{array}$ & $\begin{array}{l}\text { PT. Osram } \\
\text { Honda Prospect Motor }\end{array}$ & $\begin{array}{l}\text { Tangerang } \\
\text { Karawang }\end{array}$ & 25 & Auto 2000 & $\begin{array}{l}\text { J1. Raya Motor } 3 \text {, Sun- } \\
\text { ter } 2 \text {, Jakarta Utara }\end{array}$ \\
\hline
\end{tabular}

Tabel 4. Instansi yang Tidak Terkait Bidang Teknik Mesin Tempat Bekerja Lulusan S1 JPTM FT UNY tahun 2011-2012

\begin{tabular}{lll}
\hline No & \multicolumn{1}{c}{ Instansi } & \multicolumn{1}{c}{ Alamat } \\
\hline $\mathbf{1}$ & BRI Yogyakarta & Jl Sultan Agung 44 Yk \\
$\mathbf{2}$ & BRI cabang pacitan & Pacitan \\
$\mathbf{3}$ & Australia New Zealand Bank & Jl. Godean Km 4,5 \\
\hline
\end{tabular}

Tabel 5. Tempat bekerja lulusan JPTM FT UNY tahun 2011-2012 dibidang pendidikan

\begin{tabular}{|c|c|c|c|c|c|}
\hline No & Institusi & Alamat & No & Institusi & Alamat \\
\hline 1 & $\begin{array}{l}\text { SMK N } 1 \text { Selong, } \\
\text { Lombok Timur }\end{array}$ & Lombok Timur & $\begin{array}{c}9 \\
10\end{array}$ & $\begin{array}{l}\text { SMK Muh. I Bantul } \\
\text { SMKN } 1 \text { Purworejo }\end{array}$ & $\begin{array}{l}\text { Jl. Parangtritis } \\
\text { Purworejo }\end{array}$ \\
\hline 2 & $\begin{array}{l}\text { SMK Muhammadiyah } \\
\text { Darul Ulum }\end{array}$ & $\begin{array}{l}\text { Karangsewu, } \\
\text { Kulon Progo }\end{array}$ & 11 & SMK Ma'arif Bukateja & $\begin{array}{l}\text { Jl. Majasari, Bukateja, } \\
\text { Purbalingga }\end{array}$ \\
\hline 3 & SMK N Tambalang & Cikarang & 12 & SMK Tamtama Kroya & Jl. Semangka, Geda- \\
\hline 4 & SMK YPT Kota Tegal & Pemalang & & & wung, Kroya \\
\hline 5 & $\begin{array}{l}\text { SMK } 2 \text { Mei Bandar } \\
\text { Lampung }\end{array}$ & $\begin{array}{l}\text { Raja bosa, } \\
\text { Bandar Lam- } \\
\text { pung }\end{array}$ & 13 & $\begin{array}{l}\text { SMK Karya Teladan } \\
\text { Cawas }\end{array}$ & $\begin{array}{l}\text { Barepan, Cawas, } \\
\text { Klaten }\end{array}$ \\
\hline 6 & SMK Muh Mungkid & Magelang & & & \\
\hline 7 & $\begin{array}{l}\text { SMK Sragi Pekalon- } \\
\text { gan }\end{array}$ & Pekalongan & 14 & $\begin{array}{l}\text { PT. United Traktor (In- } \\
\text { struktur) }\end{array}$ & $\begin{array}{l}\text { Jl. Raya Bekasi Km. } 22 \\
\text { Cakung, Jakarta Timur }\end{array}$ \\
\hline 8 & SMK Ma'arif Mungkid & $\begin{array}{l}\text { Jl. Mayor Unus, } \\
\text { Kota Mungkid, } \\
\text { Magelang }\end{array}$ & 15 & $\begin{array}{l}\text { PT. Trakindo Utama } \\
\text { (Instruktur) }\end{array}$ & Jakarta \\
\hline
\end{tabular}


Tabel 6. Industri yang Terkait Bidang Teknik Mesin Tempat Bekerja Lulusan S1 JPTM FT UNY tahun 2013-2014

\begin{tabular}{rll}
\hline No & \multicolumn{1}{c}{ Nama Industri } & \multicolumn{1}{c}{ Alamat } \\
\hline $\mathbf{1}$ & PT PERTAMINA (PERSERO) & PERTAMINA AVIATION DPPU JUANDA, \\
& & Juanda International Airport, Surabaya. \\
$\mathbf{2}$ & Astra Otopart EDC łEngineering Development & Kawasan Greenland International Industrial Center \\
& Centerł & łGICłKav. AA No.2, Deltamas, Cikarang \\
$\mathbf{3}$ & PT. Sarihusada Generasi Mahardika & Jl. Jogja Solo km 16 \\
$\mathbf{4}$ & PT Bukaka & \\
$\mathbf{5}$ & PT Semen Jawa (SCG-Siam Cement Group) & Jl. Pelabuhan 2 km 11, RT 004, RW 006, Desa \\
& & Sirnaresmi, Sukabumi \\
$\mathbf{6}$ & PT. Tirta Fresindo Jaya (MAYORA Group) & Jl. Raya Pasuruan-Malang, km. 10 \\
$\mathbf{7}$ & PT Honda Prospect Motor & Jl Mitra Utara 2 Kawasan Industri Mitra Karawang \\
$\mathbf{8}$ & PT Multi Indo Mandiri & Desa Sumur Kondang RT 12, Kosambi, Klari, \\
& & Karawang \\
$\mathbf{9}$ & PT Multi Cipta Prima (Serifikasi Alat/Mesin) & Jl. Airlangga 2 Blok E no 47 Bekasi Timur \\
$\mathbf{1 0}$ & CV Dino Holzen Abadi & Jl. Songgorunggi km 4,5, Celeb, Nguter, Sukoharjo \\
$\mathbf{1 1}$ & BUMA & Kalimantan \\
$\mathbf{1 2}$ & PT KAI & Stasiun Tugu: Jl. P. Mangkubumi 1, Yogyakarta \\
& & 55271 \\
$\mathbf{1 3}$ & PT Pako Akuina & Jl. Gaya Motor No 1. Sunter Jakarta Utara \\
$\mathbf{1 4}$ & Jaya Agra Wasindo (CPO kelapa sawit) & Kel. Hulu Benteng Kec. Marubahan, Kab. Barito \\
& & Kuala \\
$\mathbf{1 5}$ & PT Fajar Surya Wisesa & Jl. Imam Bonjol, Cikarang Barat \\
$\mathbf{1 6}$ & Perkasa Flight School (PT. Mitra Aviasi Perkasa) & Bandar Udara Tunggul Wulung - Cilacap \\
$\mathbf{1 7}$ & Yamaha Musik Manufacturing Aisa & Kawasan MM 2100 Cikarang Barat Bekasi \\
$\mathbf{1 8}$ & PT Indo Green Packaging & Jl. Cangkringan Km 1 Kalasan Sleman Yogyakarta \\
$\mathbf{1 9}$ & PT. AKR Corporindo & Pelabuhan Tanjung Mas Semarang \\
$\mathbf{2 0}$ & PT TVS Motor Company Indonesia & Jl. Suryamadya Kav 1-30, Suryacipta City of \\
& & Industry, Desa Kuta Negara, Ciampel, Karawang, \\
$\mathbf{2 1}$ & PT Banyu Bang Blora Energi & Jawa Barat \\
$\mathbf{2 2}$ & PT Wings Group & Jl. Taman Bahagia 36 Cepu Blora \\
$\mathbf{2 3}$ & PT. Tri Patra Engineering and Construction & Jl. Kosambi, Karawang Timur \\
$\mathbf{2 4}$ & PT. Indo Sentosa Prada (Nisan Group) & Jl. RA Kartini Cilandak Barat Jakarta Selatan \\
& & Jl. Hayam Wuruk 161 Jember \\
\hline
\end{tabular}

Tabel 7. Instansi yang Tidak Terkait Bidang Teknik Mesin Tempat Bekerja Lulusan JPTM FT UNY tahun 2013-2014

\begin{tabular}{cll}
\hline No & \multicolumn{1}{c}{ Instansi } & \multicolumn{1}{c}{ Alamat } \\
\hline $\mathbf{1}$ & Kemenkumham & Jln. MT.Haryono No.24, Jakarta Timur 3630 \\
$\mathbf{2}$ & Bank Jateng & Jl. Ahmad Yani 20 Purworejo \\
$\mathbf{3}$ & Perpustakaan Pusat UGM & Bulaksumur, Yogyakarta \\
$\mathbf{4}$ & Pengepul sampah & Jakarta \\
$\mathbf{5}$ & Toko Emas Semar & Jl Tawangsari Sukoharjo \\
\hline
\end{tabular}

Tabel 8. Tempat Bekerja Lulusan JPTM FT UNY tahun 2013-2014 di Bidang Pendidikan

\begin{tabular}{cll}
\hline No & \multicolumn{1}{c}{ Institusi } & \multicolumn{1}{c}{ Alamat } \\
\hline $\mathbf{1}$ & SMK Boedi Oetomo Cilacap & Jl. Bali no 100 Cilacap. \\
$\mathbf{2}$ & SMK TUNAS HARAPAN PATI & Jl. RAYA Trangkil-Pati km. 4, Pati Jawa Tengah \\
$\mathbf{3}$ & SMK Muhammdiyah Bantul & Jl. Parangtritis, Manding, Bantul \\
$\mathbf{4}$ & SMAN 3 Unggulan Martapura & Jl. Adiwiyata, Desa Kotabaru Selatan, Kecamatan Martapura, \\
& & Kabupaten Ogan Komering Ulu timur, Sumatera Selatan \\
$\mathbf{5}$ & SMK Muhammadiyah 2 Borobudur & Jl. Syailendra Raya 56 Borobudur Magelang \\
\hline
\end{tabular}




\begin{tabular}{cll}
\hline $\mathbf{6}$ & SMK Muhammadiyah Mungkid & Jl. Pemandian Blabak Mungkid Magelang \\
$\mathbf{7}$ & SMK Muhammadiyah 2 Wates & Jl. Pahlawan, Nagung, Wates, Kulon Progo. \\
$\mathbf{8}$ & SMK Muhammadiyah 1 Bantul & Jl. Parangtritis km 12, Manding, Trirenggo, Bantul \\
$\mathbf{9}$ & SMK Pembaharuan Purworejo & Jl. Kesatrian 7 Purworejo \\
$\mathbf{1 0}$ & SMKN 1 Losarang & Jl. By Pass Pantura, desa Muntur, Kabupaten Indramayu \\
$\mathbf{1 1}$ & Universitas Teknologi Yogyakarta & Jalan Ringroad Utara, Jombor, Sleman, DIYogyakarta 55285 \\
\hline
\end{tabular}

Uraian pada Tabel 3 sampai dengan 8 menunjukkan bahwa lulusan S1 JPTM FT UNY tahun 2011-2014 tersebar di beberapa daerah di Indonesia, yaitu: Lampung, Sumatera Selatan, DKI Jakarta, Jawa Barat, Jawa Tengah, Di Yogyakarta, Jawa Timur, Kalimantan dan Lombok Timur. Tampak bahwa lulusan S1 JPTM FT UNT tahun 20112014 tersebar di Indonesia bagian barat dan tengah saja. Satu orang yang berada di Lombok timur bekerja sebagai guru SMK N 1 Selong, Lombok Timur. Sebagian besar lulusan yang bekerja di Industri yang terkait dengan bidang teknik mesin bekerja di DkI Jakarta dan Jawa Barat, sedang di Jawa Timur tersebar di Surabaya, Malang, Sidoarjo dan Jember.

Gambar 3 dan 4 berturut-turut memperlihatkan sebaran tempat bekerja lulusan S1 JPTM FT UNY tahun 20112012 dan tahun 2013-2014. DKI Jakarta dan Jawa Tengah adalah daerah yang paling banyak menjadi pilihan tempat bekerja lulusan S1 JPTM FT UNY. Hal ini memberi gambaran bahwa selain perkembangan ekonomi dan industri yang pesat, kedua daerah tersebut memiliki kemudahan akses terhadap pemenuhan kebutuhan hidup. Meskipun perkembangan ekonomi dan industri di Jawa Barat juga pesat namun kurang diminati sebagai tujuan tempat bekerja. Kedekatan lokasi tempat bekerja dengan lokasi kerabat dan keluarga bisa jadi merupakan faktor terhadap hal ini.

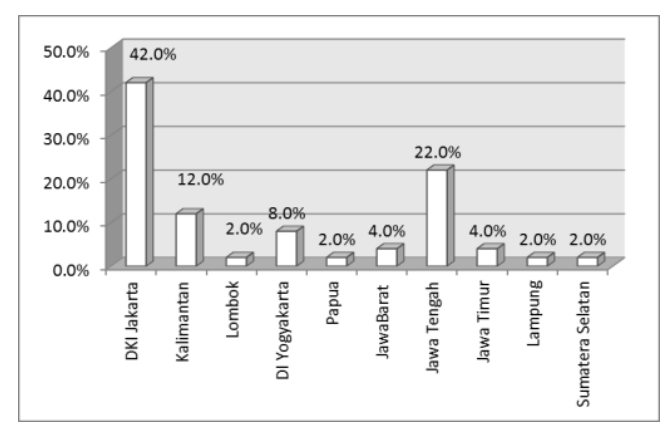

Gambar 3. Sebaran Tempat Bekerja Lulusan S1 JPTM FT UNY tahun 2011-2012

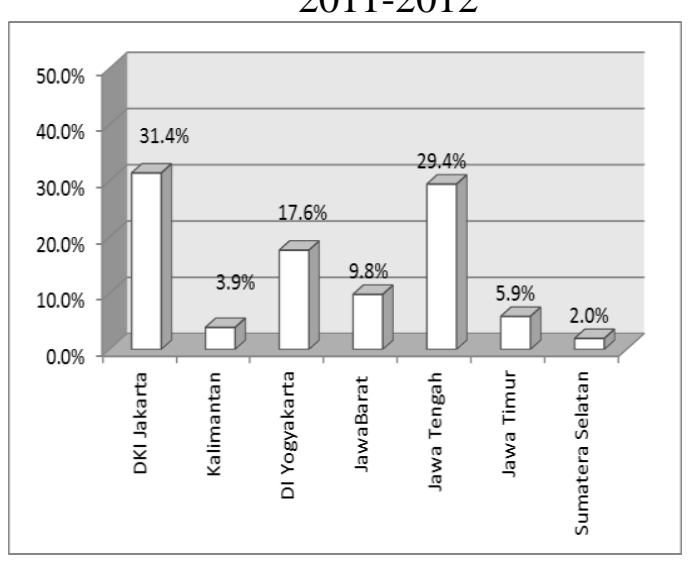

Gambar 4. Sebaran Tempat Bekerja Lulusan S1 JPTM FT UNY tahun 2013-2014 
Lulusan yang bekerja di bidang pendidikan baik SMK, SMA maupun lembaga pendidikan lainnya sebagian besar berada di institusi swasta. Hal ini terjadi baik pada lulusan tahun 20112012 maupun 2013-2014. Telaah lebih mendalam terhadap tabel 5 menunjukkan bahwa hanya 4 buah SMK Negeri yang menjadi tempat mengabdi sebagai guru dari seluruhnya 13 buah SMK yang terdata atau hanya 31\% SMK Negeri. Selebihnya adalah sebuah lembaga pendidikan dan bimbingan konseling serta dua buah industri sebagai instruktur. Telaah terhadap Tabel 8 menunjukkan kondisi yang mirip yaitu hanya sebuah SMK Negeri yang menjadi tempat mengabdi sebagai guru dari 9 buah SMK yang terdata atau hanya $11 \%$ SMK Negeri. Selebihnya terdapat di sebuah SMA Negeri dan sebuah Perguruan Tinggi Swasta.

Kondisi ini memberikan beberapa kemungkinan gambaran profil tempat bekerja lulusan JPTM FT UNY, antara lain: (1) Profesi sebagai guru kurang diminati oleh lulusan JPTM FT UNY, (2) Ketersediaan kesempatan menjadi guru di SMK Negeri (PNS) sangat terbatas, (3) Pilihan menjadi guru di SMK Swasta atau SMA di pilih karena kondisi terpaksa, (4) Kesempatan menjadi dosen di PTN sangat terbatas, (5) Penghasilan di industri lebih menjanjikan, (6) Peluang menjadi instruktur atau litbang pendidikan pada diklat-diklat di industri maupun lembaga pendidikan belum menarik perhatian sebagai sebuah peluang kerja yang menjanjikan. Bagaimanapun, masih diperlukan penelitian dan penelaahan tersendiri dan lebih mendalam untuk mengungkap dan membuktikan kebenaran kemungkinankemungkinan gambaran tersebut.

Potensi untuk bekerja sebagai instruktur di sektor industri merupakan peluang bagus. JPTM FT UNY perlu mengembangkan diversifikasi kompetensi sesuai yang dikemukakan oleh Ahmad Dardiri. (2011: 91-104). Jaringan kerjasama dengan industri selaku stake holder perlu dikembangkan secara serius agar potensi peluang kerja bagi lulusan JPTM FT UNY lebih terbuka.

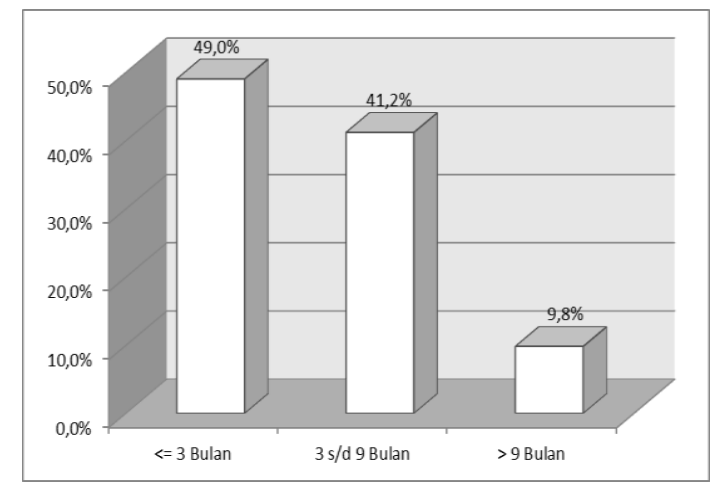

Gambar 5. Masa Tunggu Lulusan

Tahun 2011-2012 
Masa Tunggu Memperoleh Pekerjaan

Rata-rata masa tungu lulusan JPTM FT UNY 2011-2012 dalam mendapatkan pekerjaan pertama adalah 4,16 bulan terhitung sejak yudisium. Namun demikian, masa tunggu memperoleh pekerjaan dapat dikelompokkan menjadi kurang dari 3 bulan, antara 3 sampai 9 bulan dan di atas 9 bulan. Masa tunggu lulusan JPTM FT UNY tahun 2011-2012 memperoleh pekerjaan tampak pada Gambar 5. Sebanyak $49 \%$ lulusan memperoleh pekerjaan dalam waktu kurang dari 3 bulan terhitung sejak yudisium. Namun, pada kenyataannya 7 orang lulusan yang telah bekerja sebelum yudisium, baik sebagai guru, wirausahawan maupun di industri. Kondisi tersebut terjadi karena pada penelitian ini diasumsikan bahwa lulusan tersebut memiliki masa tunggu 0 (nol) bulan. Jika dihitung secara riil, artinya masa tunggu memperoleh pekerjaan dihitung negatif, maka ratarata masa tunggu lulusan JPTM FT UNY tahun 2011-2012 adalah 3,37 bulan.
Tabel 9. Profil Lulusan Tahun 20112012 yang Telah Bekerja Sebelum Yudisium

\begin{tabular}{|c|c|c|c|}
\hline No & Nama & $\begin{array}{l}\text { Tempat } \\
\text { bekerja }\end{array}$ & $\begin{array}{c}\text { Telah } \\
\text { bekerja } \\
\text { sebelum } \\
\text { yudis- } \\
\text { ium }\end{array}$ \\
\hline 1 & $\begin{array}{l}\text { Rambat } \\
\text { raharjo }\end{array}$ & $\begin{array}{l}\text { PT.Kobeindo } \\
\text { Tractor }\end{array}$ & 2 bulan \\
\hline 2 & $\begin{array}{l}\text { Eko agus } \\
\text { prasetyo }\end{array}$ & $\begin{array}{l}\text { Indomobil } \\
\text { Nissan }\end{array}$ & 1 bulan \\
\hline 3 & $\begin{array}{l}\text { Andri } \\
\text { purba lak- } \\
\text { sono }\end{array}$ & $\begin{array}{l}\text { SMK Muham- } \\
\text { madiyah Darul } \\
\text { Ulum }\end{array}$ & 8 bulan \\
\hline 4 & $\begin{array}{l}\text { Agus } \\
\text { setiyo } \\
\text { bangun }\end{array}$ & Wiraswasta & 9 bulan \\
\hline 5 & $\begin{array}{l}\text { Ngudi } \\
\text { prakoso }\end{array}$ & $\begin{array}{l}\text { SMK YPT } \\
\text { Kota Tegal }\end{array}$ & 7 bulan \\
\hline 6 & Surono & $\begin{array}{l}\text { SMK Karya } \\
\text { Teladan Cawas }\end{array}$ & 8 bulan \\
\hline 7 & $\begin{array}{l}\text { Aris Agus } \\
\text { Santoso }\end{array}$ & $\begin{array}{l}\text { Wirausaha } \\
\text { Budidaya Bu- } \\
\text { rung Parkit }\end{array}$ & 5 bulan \\
\hline
\end{tabular}

Secara rinci profil 7 orang lulusan JPTM FT UNY tahun 2011-2012 yang telah memperoleh perkerjaan sebelum yudisium tersebut tampak pada tabel 9 . Dari tabel 9 tampak bahwa 3 orang lulusan telah menjadi guru di SMK Swasta, 2 orang bekerja di industri dan 2 orang berwirausaha. Hal ini memperjelas bahwa lulusan JPTM FT UNY banyak diminati oleh SMK-SMK swasta bahkan sebelum mereka di yudisium.

Kondisi hampir sama juga terjadi pada lulusan JPTM FT UNY 2013-2014. Rata-rata masa tunggu lulusan memperoleh pekerjaan adalah 4,11 bulan 
terhitung sejak yudisium. Masa tunggu lulusan JPTM FT UNY tahun 2013-2014 memperoleh pekerjaan yang dikelompokkan menjadi kurang dari 3 bulan, antara 3 sampai 9 bulan dan di atas 9 bulan (Gambar 6). Sebanyak 48,1\% lulusan memperoleh pekerjaan dalam waktu kurang dari 3 bulan terhitung sejak yudisium. Namun pada kenyataannya 6 orang lulusan yang telah diterima bekerja sebelum yudisium, baik sebagai guru, wirausahawan maupun di industri. Kondisi tersebut terjadi karena pada penelitian ini diasumsikan bahwa lulusan tersebut memiliki masa tunggu 0 (nol) bulan. Jika dihitung secara riil, artinya masa tunggu memperoleh pekerjaan dihitung negatif, maka ratarata masa tunggu lulusan JPTM FT UNY tahun 2013-2014 adalah 3,73 bulan.

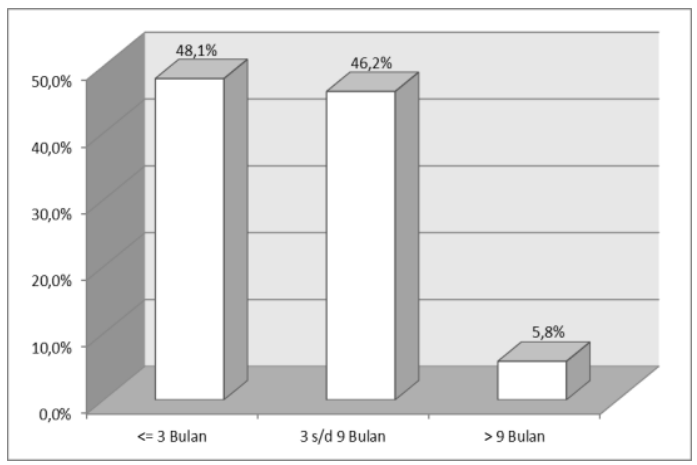

Gambar 6. Masa Tunggu Lulusan Tahun 2013-2014
Tabel 10. Profil lulusan tahun 20132014 yang telah bekerja sebelum yudisium

\begin{tabular}{|c|c|c|c|}
\hline No & Nama & Tempat bekerja & $\begin{array}{c}\text { Telah } \\
\text { bekerja } \\
\text { sebelum } \\
\text { yudisium }\end{array}$ \\
\hline 1 & $\begin{array}{l}\text { Fendi Tri } \\
\text { Wibowo }\end{array}$ & SMK Leonardo & 4 bulan \\
\hline 2 & $\begin{array}{l}\text { Akhmad } \\
\text { Adib } \\
\text { Setyawan }\end{array}$ & $\begin{array}{l}\text { SMK Muham- } \\
\text { madiyah } 2 \\
\text { Borobudur }\end{array}$ & 7 bulan \\
\hline 3 & $\begin{array}{l}\text { Muham- } \\
\text { mad Yusuf } \\
\text { Ikhsani }\end{array}$ & $\begin{array}{l}\text { SMK Muham- } \\
\text { madiyah Mung- } \\
\text { kid }\end{array}$ & 2 bulan \\
\hline 4 & $\begin{array}{l}\text { Novi Hi- } \\
\text { dayat }\end{array}$ & $\begin{array}{l}\text { SMK Muham- } \\
\text { madiyah } 1 \\
\text { Bantul }\end{array}$ & 3 bulan \\
\hline 5 & $\begin{array}{l}\text { Yusuf Dwi } \\
\text { Wijanarko }\end{array}$ & $\begin{array}{l}\text { PT Honda } \\
\text { Prospect Motor }\end{array}$ & 1 bulan \\
\hline 6 & $\begin{array}{l}\text { Rahmad } \\
\text { Nur Hi- } \\
\text { dayat }\end{array}$ & $\begin{array}{l}\text { Wirausaha } \\
\text { Budidaya Jamur }\end{array}$ & 3 bulan \\
\hline
\end{tabular}

Secara rinci profil 6 orang lulusan JPTM FT UNY tahun 2013-2014 yang telah memperoleh perkerjaan sebelum yudisium tersebut tampak pada tabel 10 . Tampak bahwa 4 orang lulusan telah menjadi guru di SMK Swasta, 1 orang bekerja di industri dan 1 orang berwirausaha. Seperti kondisi pada lulusan tahun 2011-2012, jelas bahwa lulusan JPTM FT UNY banyak diminati oleh SMK-SMK swasta bahkan sebelum mereka di yudisium.

Masa tunggu kelompok I maupun II pada penelitian ini dapat dinyatakan sejalan dengan masa tunggu lulusan S1 
kependidikan Fakultas Teknik Universitas Negeri Yogyakarta tahun 2006-2010. (Sukardi, 2011: 196-201). Meskipun lulusan JPTM FT UNY tahun 2011-2014 dengan masa tunggu kurang dari 3 bulan masih di bawah 50\%, yang berarti lebih rendah dibanding hasil penelusuran $\mathrm{Su}-$ kardi, namun lulusan dengan masa tunggu lebih dari 9 bulan lebih tinggi, yaitu di atas 9\%. Bahkan pada kenyataannya terdapat lulusan yang telah bekerja sebelum lulus.

Para lulusan yang telah bekerja sebelum yudisium memberikan gambaran bahwa kompetensi lulusan JPTM FT UNY cukup diakui oleh stake holder pengguna lulusan. Hal yang perlu dicatat adalah menjadi guru di SMK swasta menjadi pilihan tempat bekerja bagi sebagian besar lulusan tersebut. Hal ini mungkin karena SMK swasta lebih terbuka menawarkan lowongan pekerjaan bagi calon-calon lulusan JPTM FT UNY. Namun demikian, lowongan pekerjaan sebagai guru di SMK-SMK swasta sepi peminat. Kondisi ini terbukti dengan lebih banyak lulusan JPTM FT UNY memilih bekerja di indsutri. Fenomena ini perlu diselidiki lebih mendalam untuk mengetahui kebenarannya. Bila hal ini terbukti benar, maka JPTM FT UNY perlu melakukan langkah-langkah strategis sebagai antisipasi terkait keadaan ini. Beberapa contoh langkah-langkah yang dapat ditempuh oleh JPTM FT UNY antara lain: (1) memberi sosialisasi kepada calon lulusan ketersediaan lapangan pekerjaan sebagai guru SMK swasta; (2) banyak menjalin kerjasama dengan SMK-SMK swasta disegala aspek terkait pendidikan; (3) mendorong mahasiswa melakukan kunjungan ke SMK-SMK swasta; dan sebagainya. Sudah barang tentu pelaksanaan langkah-langkah antisipasi ini membutuhkan dukungan dan kerjasama instansi-instansi terkait, seperti: UNY, Pemda/Pemkot setempat, SMK-SMK terkait.

\section{Relevansi Kompetensi yang ditetapkan di JPTM FT UNY dengan Kompetensi yang dibutuhkan di Pasar Kerja}

Kesesuaian bidang pekerjaan lulusan JPTM FT UNY tahun 2011-2012 dan tahun 2013-2014 berturut-turut disajikan pada Gambar 7 dan 8. Tampak bahwa bidang pekerjaan lulusan JPTM FT UNY di atas $88 \%$ sesuai dengan bidang ilmu yang dipelajari di bidang keteknik-mesinan di industri maupun bidang pendidikan baik sebagai guru SMK maupun instruktur di diklat-diklat. 


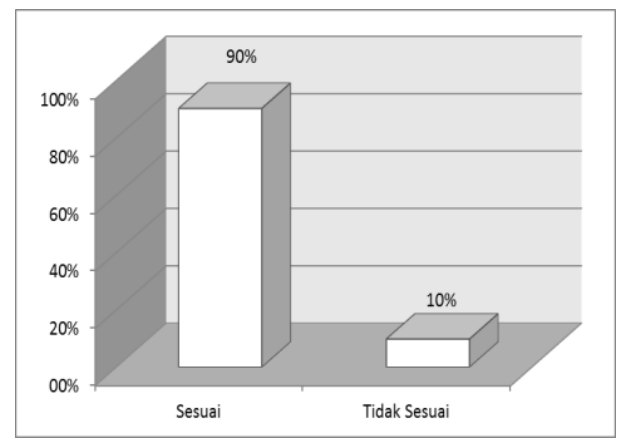

Gambar 7. Kesesuaian Bidang Pekerjaan Lulusan Tahun 2011-2012

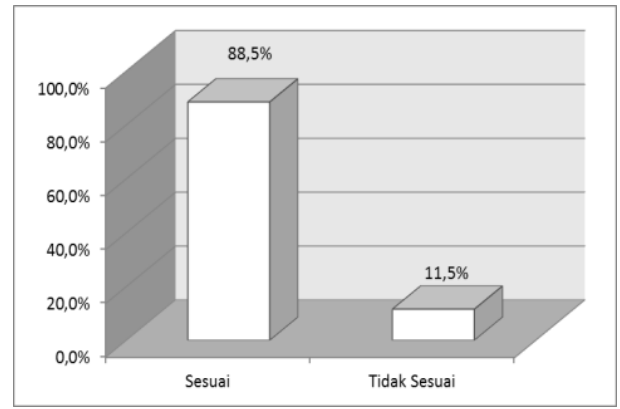

Gambar 8. Kesesuaian Bidang Pekerjaan Lulusan Tahun 2013-2014

Bidang pekerjaan yang tidak sesuai dengan bidang ilmu yang ditemukan pada kelompok I antara lain:

(1) Wirausaha (budidaya burung parkit);

(2) Customer service dan Teknisi ATM di Bank BRI; (3) Front Laeder di Bank BRI; (4) Freelance Kartu Kredit di Australia New Zealand Bank. Sedang bidang pekerjaan yang tidak sesuai dengan bidang ilmu yang ditemukan padakelompok II antara lain: (1) Wirausaha (budidaya jamur dan distributor minuman ringan); (2) Karyawan Pembukuan pada pengepul sampah; (3) Staff Intelejen di Kemenkuham; (4) Teller Pajak
PBB di Bank BPD Jateng; (5) Marketing di Toko Emas Semar, Sukoharjo.

Hal ini memberi gambaran bahwa sebagian kecil lulusan JPTM FT UNY belum memperoleh pekerjaan yang sesuai. Kondisi ini perlu menjadi catatan bagi JPTM FT UNY mengenai sustainabilty lulusan. Bagaimanapun, beberapa bidang pekerjaan yang tidak sesuai yang diperoleh lulusan JPTM FT UNY adalah juga bidang pekerjaan yang menjanjikan yang bisa jadi merupakan kelebihan yang dimiliki oleh lulusan-lulusan JPTM FT UNY. Lebih lanjut, terungkap pula bahwa matakuliah Psikologi Pendidikan menjadikan lulusan JPTM FT UNY mampu mengendalikan, mengatur dan mengarahkan karyawan sehingga salah satu lulusan JPTM FT UNY tahun 2014 dipercaya menduduki jabatan Manajer Personalia. Matakuliah Kewirausahaan merupakan matakuliah yang membekali mahasiswa dalam merintis wirausaha. Manajemen Industri dan Maintenance merupakan matakuliah yang menurut sebagian besar lulusan JPTM FT UNY sangat mendukung pekerjaan di industri. Hasil penelusuran oleh Thomas Sukardi (2011: 196-201) juga menunjukkan fenomena yang sama.

Hasil penelitian menunjukkan bahwa sebagain besar lulusan telah 
bekerja dengan dengan bidang pekerjaan yang beragam terutama sebagai guru SMK dan bekerja di industri. Disamping itu terdapat alumni yang melanjutkan studi ke jenjang S2. Hal ini menunjukkan bahwa daya serap lulusan termasuk dalam kategori tinggi. Bidang pekerjaan dapat mencerminkan profesi apa saja yang dapat ditekuni lulusan. Bila dilihat dari bidangnya tampak bahwa sebagian besar lulusan bekerja di industri bidang teknik mesin, diikuti sebagai guru, wirausaha maupun bekerja dalam bidang jasa. Hal ini memberikan informasi bahwa lulusan selain sebagai guru, juga dapat berperan di industri bidang teknik mesin. Hal ini selaras dengan bekal yang diberikan kepada mahasiswa berupa ilmi keguruan dan keahlian dalam bidang keteknikan minimal setara dengan diploma tiga.

Dilihat dari tempat bekerja, tampak bahwa sebagian besar alumni bekerja dalam lingkup Jawa, Sumatera, dan Kalimantan. Sebagian besar lulusan bekerja dalam wilayah DKI Jakarta (terutama industri), Jawa Tengah, dan DIY. Hal ini merupakan masukan berharga guna memotivasi mahasiswa untuk dapat berperan tidak hanya di Jawa saja tetapi juga di wilayah yang lain bahan dalam lingkup regional maupun global.

Dilihat dari sisi masa tunggu terlihat bahwa rata-rata masa tunggu lulusan untuk mendapatkan pekerjaan adalah 4 bulan. Lebih menggembirakan bahwa sebagian besar lulusan mendapat pekerjaan dibawah 3 bulan. Hal ini menjadi bukti bahwa daya serap lulusan JPTM FT UNY sudah baik. Langkah yang perlu dilakukan tentunya adalah semakin memperpendek masa tunggu lulusan untuk memperoleh pekerjaan.

Relevansi kompetensi yang ditetapkan oleh prodi dengan kebutuhan di lapangan keraja data dicermati dari bidang-bidang pekerjaan yang diraih lulusan. Bidang pekerjaan utama lulusan adalah bekerja di industri diikuti guru, karyawan bidang jasa, dan wirausaha. Hal ini semakin menguatkan perumusan profil lulusan yang tidak hanya sebagai guru/tenaga pendidik tetapi bekal keteknikan yang diberikan ternyata merupakan modal berharga untuk meraih pekerjaan. Oleh karenanya tepat bila profil yang dirumuskan dalam kurikulum tidak hanya menyiapkan lulusan sebagai guru/pendidik saja, tetapi perlu perluasan bidag pekerjaan yang relevan 
seperti tenaga kependidikan, karyawan/instruktur di industri, maupun wirausaha.

\section{Keterbatasan Peneliitian}

Responden yang berhasil dihubungi dan memberikan data pada penlitian ini hanya sekitar 50\% dari keseluruhan lulusan JPTM tahun 2011-2014. Bebeapa penyebab hal ini adalah: Data nomor telepon, alamat e-mail, WA ataupun media lain yang dapat digunakan sebagai sarana untuk memperoleh data tidak tersedia dalam data base JPTM; Nomor telpon mahasiswa sudah terdata dalam data base JPTM, namun saat dihubungi nomor tersebut sudah tidak aktif; Ketika digunakan media snowball, terkadang data yang diperoleh dari responden yang berhasil dihubungi kurang lengkap. Lebih jauh, seringkali nomor kontak yang diperoleh dari seorang responden tentang reponden lainnya saat dihubungi tidak ada respon.

\section{KESIMPULAN}

Sebagian besar lulusan Jurusan Pendidikan Teknik Mesin Prodi S1 telah mendapatkan pekerjaan dengan rata-rata masa tunggu 4 bulan; bidang pekerjaan terdiri dari pendidik, wirausaha, karyawan yang tidak terkat dengan bidang teknik mesin, dan karyawan yang terkait dengan bidang teknik mesin; sebagian besar lulusan bekerja di industri bidang teknik mesin.

Relevansi kompetensi menunjukkan bahwa bidang pekerjaan lulusan JPTM FT UNY di atas $88 \%$ sesuai dengan bidang ilmu yang dipelajari dibidang teknik me4sin di industri maupun bidang pendidikan sebagai guru SMK maupun instruktur di lembaga diklat. Lulusan lebih banyak bekerja disektor industri diikuti dengan sektor yang lain seperti pendidik, wirausaha, dan karyawan di bidang jasa.

Berdasarkan simpulan di atas dapat dikemukakan saran sebagai berikut ini . Hasil peneitian ini hendaknya segera ditindaklanjuti seba-gai bahan evaluasi kurikulum agar lulusan yang nantinya dihasilkan benar-benar sesuai dengan kebutuhan dunia kerja. Perlu dilakukan penelitian-penelitian lanjutan untuk mengungkap fakta-fakta yang terekam secara lebih mendalam. Penelitian-penlitian lanjutan ini dapat menjadi dasar bagi JPTM FT UNY khusunya dan FT UNY umumnya dalam membuat kebijakan strategis maupun dalam menjalin kerjasama. JPTM FT UNY perlu meningkatkan kerjasama dengan SMK-SMK baik swata maupun negeri 
serta industri dan perusahaan-perusahaan selaku stakeholder serta pemda/pemkot.

Sistem jaringan berbasis internet untuk memudahkan penjaringan datadata yang perlu segera dibuat untuk menelusuri lulusan JPTM FT UNY. Laman http://ppk.lppmp.uny.ac.id/questionnaire/reply dan http://pendidikan-teknikmesin.ft.uny.ac.id/alumni disarankan lebih diefektikan lagi agar benar-benar berfungsi sebagai sumber data utama dalam setiap studi penelusuran yang dilakukan oleh setiap prodi di lingkungan UNY. Jika perlu dibuat menjadi semacam media komunikasi antar lulusan dengan format mirip situs-situs media sosial yang saat ini telah menjadi trend.

\section{DAFTAR PUSTAKA}

Ahmad Dardiri. (2011). Diversifikasi Kompetensi Lulusan Pendidikan Dan Latihan Vokasi untuk Lebih Kompetitif. Teknologi Dan Kejuruan, (34) 1, 91 - 104.

Cohen R. N. (2004). Introducing tracer studies: Guidelines for implementing Tracer Studies in early childhood programmes. Diakses tanggal 22 Oktober 2011,dari http:// www.bernardvanleer.org

Saliman, dkk., (2015). Tracer Study Jurusan Pendidikan IPS Pemetaan Dan Identifikasi Keterserapan di Dunia Kerja Lulusan Jurusan Pendidikan Ilmu Pengetahuan Sosial Fakultas Ilmu Sosial Universitas Negeri Yogyakarta Tahun 2014. JIPSINDO. 1(2), 83 - 100.

Setiya Fakhrulisah dan Tamsil Muis. (2016). Studi Penelusuran (Tracer Study) Alumni Program Studi Pendidikan Luar Biasa Fakultas Ilmu Pendidikan Universitas Negeri Surabaya Tahun Wisuda 2000-2004. Jurnal BK UNESA, (6) 1.

Thomas Sukardi. (2011). Studi Penelusuran Lulusan S1 Kependidikan Fakultas Teknik Universitas Negeri Yogyakarta. Jurnal Pendidikan Teknologi dan Kejuruan, 20(2), 196 - 201.

Ugwuonah, G.E. \& Omeje, K.C. (1998). Higher education and the demands of manpower development in the Nigerian manufacturing sector: An empirical study of Enugu and Anambra States. Diakses 19 Oktober 2011, dari http://erepo.usiu.ac.ke/bitstream/handle/$\underline{11732 / 1582 / \text { ugwomej.pdf? sequence }=2 \& \text { is Allowed }=y}$

USAID. (1998). Tracer Studies. Diakses pada tanggal 9 Agustus 2011, dari http://pdf.usaid.gov/pdf_docs/PNACP405.pdf 